\title{
DRAWING DETAILS IN AN OLD CHURCH
}

I HEAR the bell-rope sawing, And the oil-less axle grind, As I sit alone here drawing What some Gothic brain designed; And I catch the toll that follows

From the lagging bell, Ere it spreads to hills and hollows

Where people dwell.

I ask not whom it tolls for, Incurious who he be; So, some morrow, when those knolls for One unguessed, sound out for me, A stranger, loitering under

In nave or choir, May think, too, 'Whose, I wonder ?'

But not inquire.

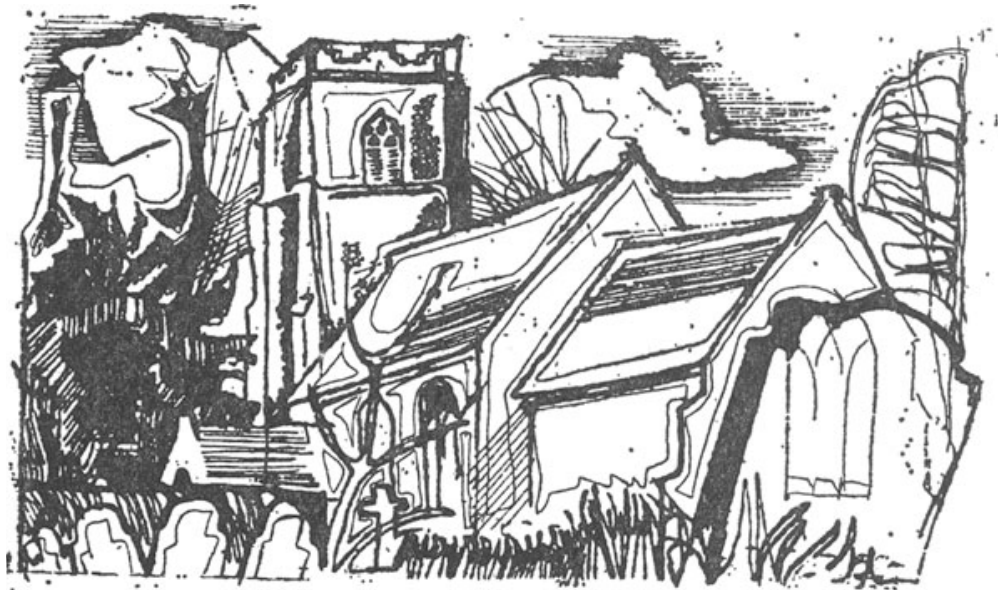

